\title{
InSAR analysis of Sentinel-1 data for monitoring landslide displacement of the north-eastern Copou hillslope, Iaşi city, Romania
}

\author{
Nicuşor Necula \\ Department of Geology, Geography and Geology \\ Faculty \\ Alexandru Ioan Cuza University of Iaşi \\ Iaşi, Romania \\ neculanicusor93@gmail.com
}

\author{
Mihai Niculiţă \\ Department of Geography, Geography and Geology Faculty \\ Alexandru Ioan Cuza University of Iaşi \\ Iaşi, Romania \\ mihai.niculita@uaic.ro
}

\author{
Giulia Tessari, Mario Floris \\ Department of Geoscience \\ University of Padova \\ Padova, Italy \\ giulia.tessari.1@unipd.it, mario.floris@unipd.it
}

\begin{abstract}
This work is aimed at showing the potential use of Synthetic Aperture Radar interferometry (InSAR) for landslide investigation and for the evaluation of the slope displacement over time and identification of unstable areas for the north-eastern Copou hillslope. The available Sentinel1 data have been processed using Advanced Differential Interferometry (A-DInSAR) techniques which includes Permanent Scatterers Interferometry (PSI) and Small BAseline Subset (SBAS).
\end{abstract}

Starting from two or more SAR phase images for the same area with different time acquisition it is possible to measure small deformations of the ground surface by using remote sensing techniques such as InSAR. The detection of ground displacement can be derived if the topographic phase contribution is removed from the generated interferogram. The generation and subtraction of synthetic interferogram allows to create displacement maps, and to overcome its major limitations (temporal and geometric decorrelations, phase unwrapping, the atmospheric component) different algorithms have been developed belonging to two main families: the Permanent (Persistent) Scatterers Interferometry (PSI) and the Small BAseline Subset (SBAS). Even though the techniques are exploiting different strategies, both of them were developed with the same purpose, to identify and measure the ground deformations with sub-centimeter precision.

For our study area, the north-eastern part of Iaşi city, over 100 different phase Sentinel-1 images kindly provided by ESA have been processed using both techniques (PSI and SBAS), with the stacking tool of the software Sarscape. The SAR images covers a period of more than 2 years (October 2014 - January 2017) and include both orbits: ascending and descending.
Iaşi area is affected by slow moving landslides, which make our testing area to have a good environmental setting for the above mentioned techniques to be applied. According to our results, the Ţicău unstable area has been identified to have in several sectors considerable velocity values, greater than $3 \mathrm{~mm} /$ year. These values represent the mean velocity along line of sight (LOS) and illustrate the displacement trend of ground surface over the study period.

Keywords - landslide; SAR interferometry; Sentinel-1; PSI; SBAS; Iași; Romania

\section{INTRODUCTION}

Recent advances in radar based techniques and higher quality information from different type of sensors have significantly improved the accuracy of monitoring ground deformations and increased its applicability for various natural hazardous phenomena [1]. A powerful remote sensing approach which is capable to measure the low rates of surface displacements using interferograms is based on Synthetic Aperture Radar Interferometry (InSAR) techniques. An interferforogram is created considering the information in the phase difference of two SAR images acquired in different times over the same area.

The Earth surface displacements is manifesting as vertical and horizontal movement conducting to a tridimensional displacement vector. This case is specific to landslides behavior which represent phenomena whose natural diffuse displacement is occurring along the slope and is highly influenced by the inclination and the aspect of the slope [2]. While in the case of subsidence and uplift phenomena the vertical displacement is dominant, for landslides, the flow mechanism has an important component along the inclination angle of the slope which 
has a great contribution to the horizontal displacement, as well as toward the aspect, that indicates the direction of sliding in the horizontal plane. However, because of the nearly polar orbits of the SAR satellites, the north-south component of displacement cannot be measured unless additional information on ground motion is known [3].

Since the beginning of the 2000s, different methods have been proposed in order to calculate long term surface displacements. The two main algorithms are the Permanent Scatterers Interferometry (PSI) $[4,5]$ and the Small BAseline Subset (SBAS) [6]. Some other algorithms have been developed to adapt these methods to specific needs, or attempt to combine both of them to obtain better results.

\section{STUDY AREA}

The study area, located in the north-eastern part of Copou hillslope (Fig. 1), has been chosen to identify very slow movements of stabilized landslides. Since 1900, landslide reactivations sometimes ended with destruction of houses and damage to streets [7, 8], but in recent years after remediation works it is considered as a stable area. However, considering its past behavior (several reactivations, one in the ' 42 and the other in '69) [7, 8] and the geological environment (clayey and sandy layers with a fluvial terrace and slope deposits caprock), slow movements which can affect the structure of houses are expected. This context represents a good opportunity for satellite image analysis to identify possible critic (unstable) areas and trying to prevent future damages to inhabitants, buildings and infrastructure.

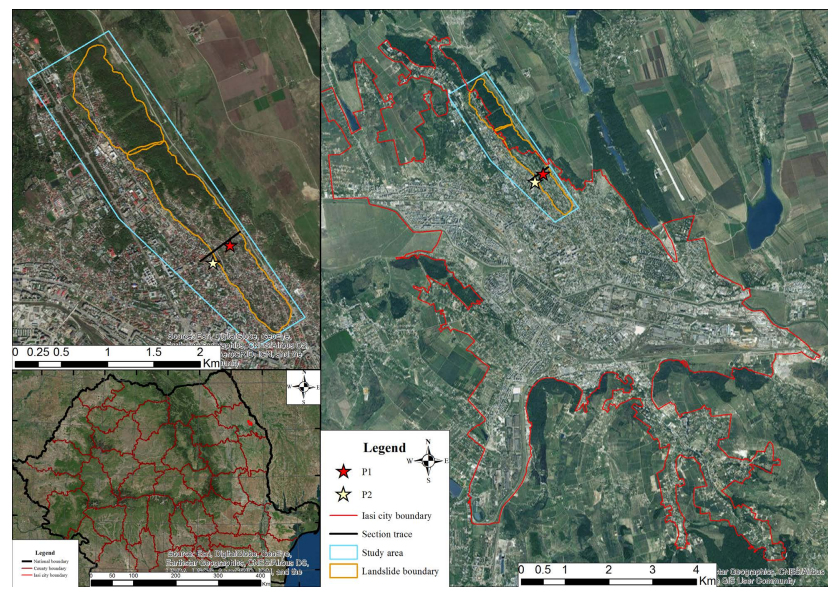

Fig. 1. Geographical location of the study area within Iași municipality

The main landslide conditioning factor is the geology of this area which consists of Bassarabian (Middle Sarmatian) clays interbedded with sand layers and covered by quaternary deposits (fluvial and slope deposits, loess Fig. 2). The caprock of permeable loess and slope deposits allow the formation of an aquifer in the basal sand and gravel layer, at the contact with the impermeable clays [8]. Permanent springs are known in the area, and especially after consecutive rainy autumns, winters and springs [8], or during summer storms [7]. Reactivations of the scarp of the landslide body happened, mainly affecting portion of the hillslope where drainage measures were not implemented before (the reactivations migrated from the southern part to the northern part of the hillslope) [7, 8].

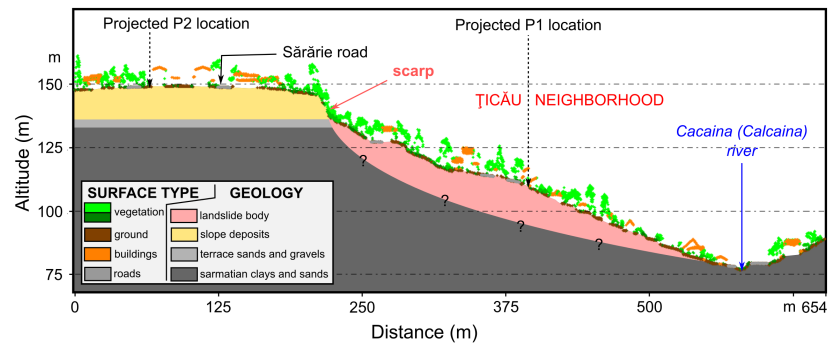

Fig. 2. Geomorphological section through Copou north-eastern hillslope (the direction appears in Fig. 1 as a black line)

At present, the landslide is stabilized by drainage wells and drainage trenches, mainly located in the scarp area. Furthermore, surface deformation is stopped by passive stabilizing infrastructure (anchors, gabion and concrete walls - Fig. 3).

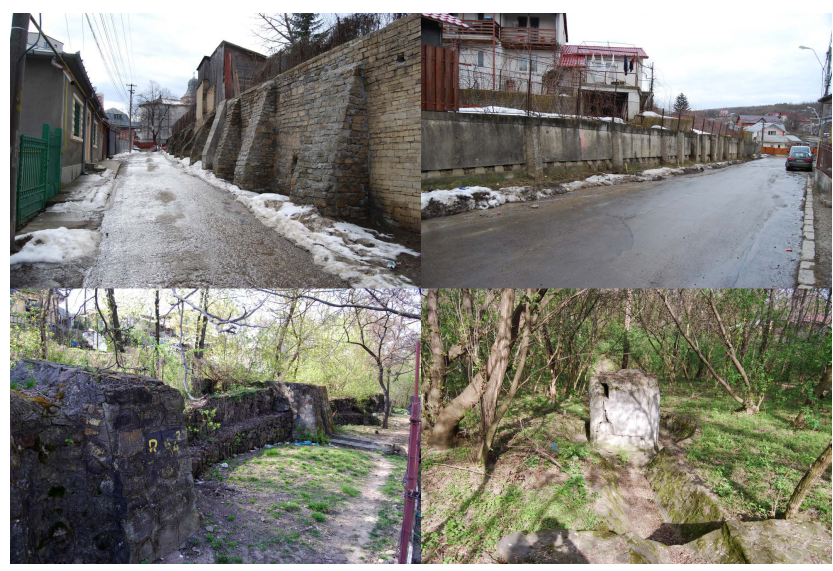

Fig. 3. Passive mechanic infrastructure used for the stabilization of the hillslope

\section{METHODS}

For our study case, good framework of the landslide which is characterized by low rates of displacement with a dominant west to east sliding direction, made possible to apply SAR interferometry techniques. Thus, using the Sentinel-1 data provided by ESA, the two main techniques, PS and SBAS, have been used to obtain information about the velocity and the evolution of displacement in Line of Sight (LOS) direction.

The Permanent Scatterers algorithm [2 - 5] considers the phase information of isolated targets characterized by high_reflectivity and temporal stability of the phase signal in all the SAR data with respect to the master image. Although this technique presents a significant advantage for landslide monitoring with respect to in situ measurements, it is dependable to coherent targets, for this reason urbanized areas are preferred for this technique to be applied. The dense vegetation which covers a part of the landslide made impossible to obtain any results from PS technique, for this reason the SBAS approach was more appropriate in order to have more information over the area. The Small Baseline Subset (SBAS) method $[3,6]$ is relaying on the small baseline between 2 time acquisitions. Practically, the algorithm is pairing all the images which are defined by the threshold parameters for temporal and normal baseline. The main advantage of this technique is that it takes into account also low coherence areas to extend the spatial coverage of the final result, being a 
useful tool for vegetated areas characterized by diffuse targets. Moreover, this technique can be used when few SAR images are available because this algorithm increases the redundancy of the created interferograms.

Despite the fact that these approaches rely on different strategies they have been developed and improved for the same purpose, to overcome the main limitations of DInSAR techniques, reducing temporal and geometric decorrelations, supporting phase unwrapping step and estimating the atmospheric component, in order to obtain results with sub-centimeter precision.

More than 100 Sentinel-1 SAR data acquired for both ascending and descending orbits were processed, covering a time interval of approximately two years, from October 2014 to January 2017. The Interferometry Stacking tool of SARMAP's SARscape software package 5.4 has been used.

\section{RESUlTS AND DISCUSSIONS}

Based on the analysis of Sentinel-1 images, velocity maps along the line of sight direction for both tracks using PS and SBAS techniques have been created. For ascending tracks (Fig. 4) velocity values ranging from -3 to -10 $\mathrm{mm} / \mathrm{y}$, and locally even higher, have been obtained inside the landslide compared with the stable points outside of its border. To overcome the lack of information in the area with dense vegetation the SBAS technique was also considered, but unfortunately low coherence area influenced the unwrapping step and naturally the final results of SBAS.

Excluding the vegetated area where no results came by, the SBAS output for the rest of the area is similar with the one obtained through PS method which make the analysis to be consistent. The evidence of surface displacement was also checked and found in the field (Fig. 6): wall cracks, wall buldging and tilted trees.

The time series of displacements for two different points (Fig. 7) have also been plotted to illustrate the difference between a moving point (P1 - red star) located in the sliding area and a stable one (P2 - yellow star) outside of its border. The displacement trend of each point is representative for the area they belong to, for the unstable area displacement values over $2 \mathrm{~cm} / \mathrm{y}$ have been recorded.

The projection of results along the vertical and eastwest direction was also calculated using the mean velocity datasets from PS ascending and descending orbits [9, 10]. The projected results appears to be in accordance with the small inclination values of the slope, the landslide being characterized by a west to east movement direction rather than a vertical one.

\section{CONCLUSIONS}

The use of interferometry for landslide assessment appears to be convenient in order to detect the deformation produced in the affected area making InSAR techniques a helpful tool. Although it has some limits, its low costeffectiveness and the huge number of points with high precision obtained for large areas in a fast way make InSAR techniques comparable with the standard methods such as GPS surveys and optical leveling, and certainly reliable for future investigations of slope instability.

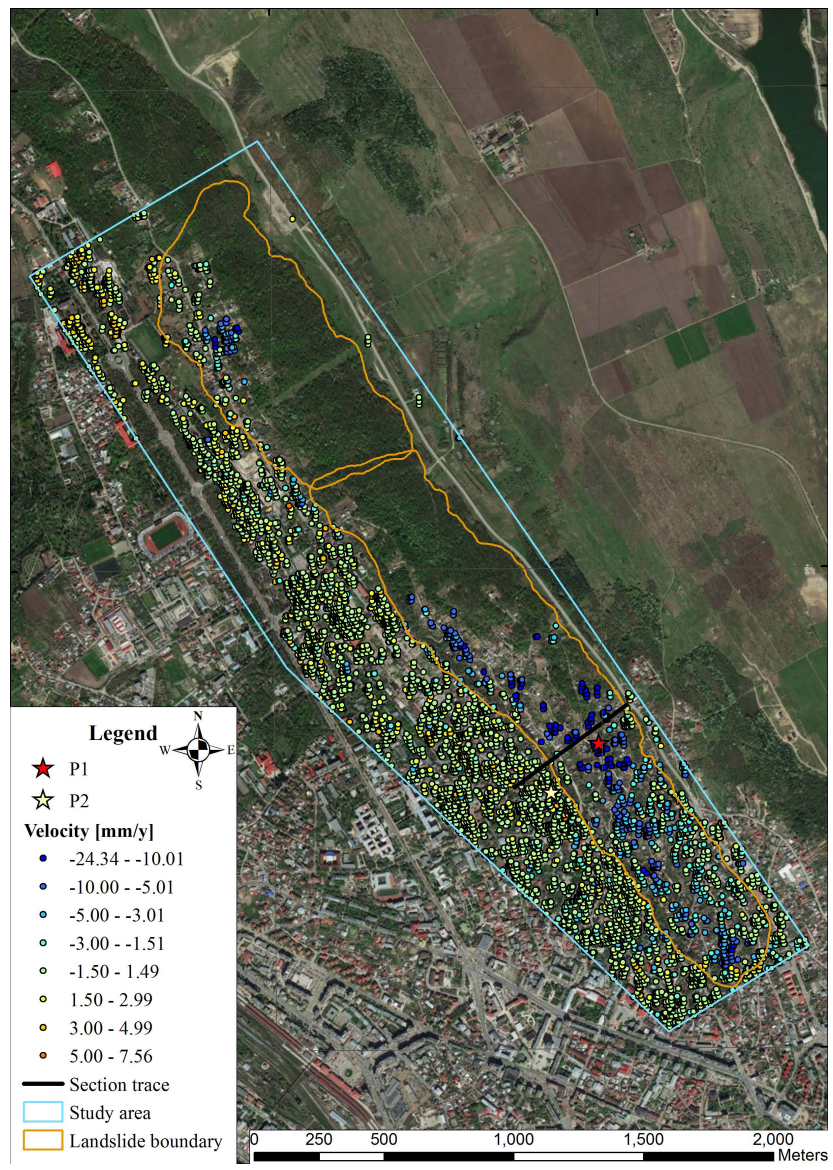

Fig. 4. PS results

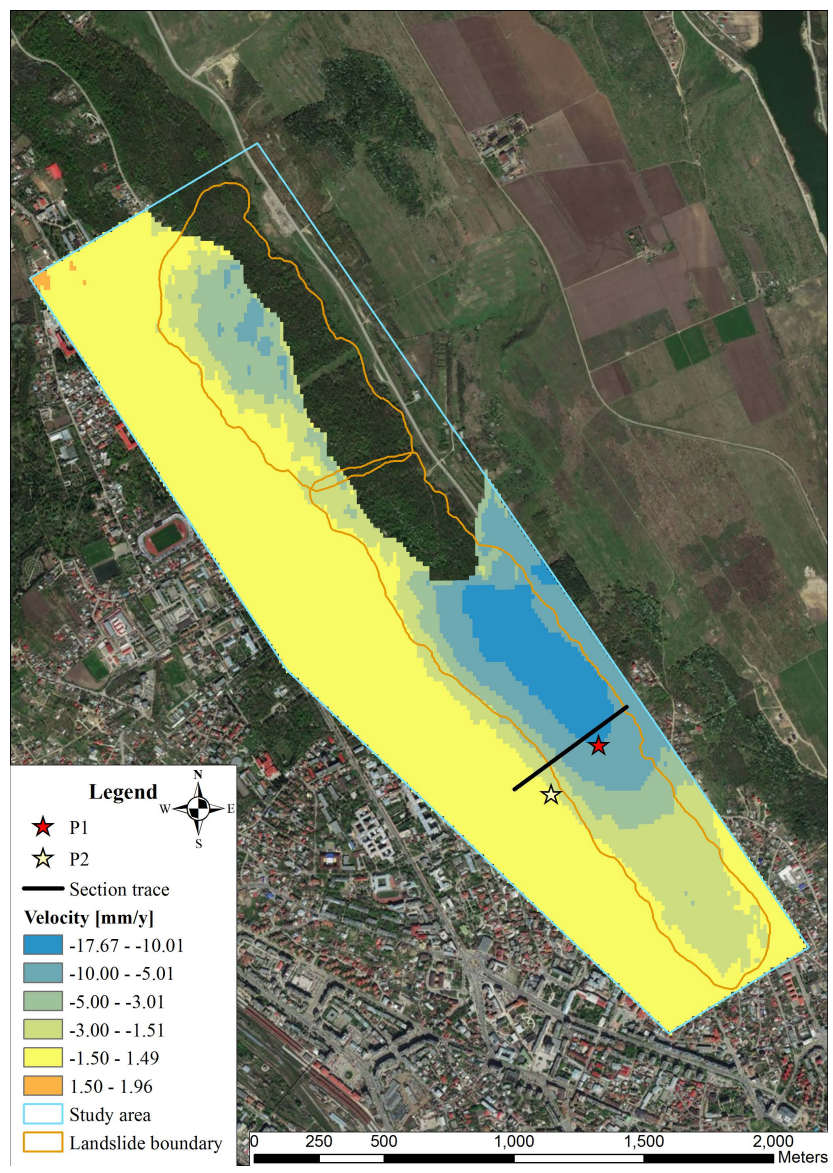

Fig. 5. SBAS results. 


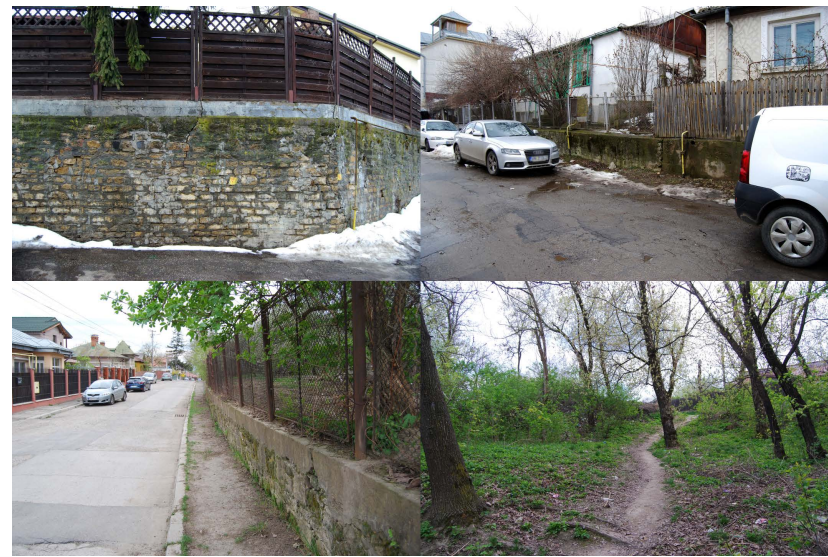

Fig. 6. Evidences of surface displacement: upper left and right - wall cracks, bottom left - wall buldging, bottom right - tilted trees.

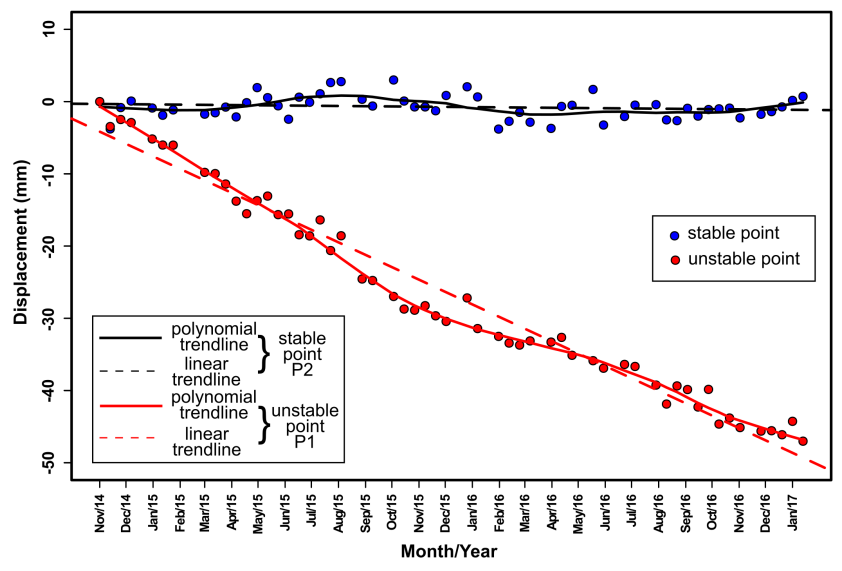

Fig. 7. Displacement rates for a stable and unstable PS point (the location of the points are shown in Fig. 1: stable point - P2 yellow star, unstable point - P1 - red star).

The ability to generate displacement information on stabilized landslides, as is the case for Copou hillslope is crucial to identify hazardous areas, where reactivations might occur. Considering that the last climatic cycle (after the '90) is a dry one, and future rainy periods coupled with a change in house constructions style (one level small houses are replaced by 2-3 level villas) will increase the risk associated with landslide reactivations.

Nevertheless, the analysis of Sentinel-1 data using PS and SBAS technique identified moving areas along the
Copou hillslope where deformations of $10 \mathrm{~mm} / \mathrm{y}$ occur. However, a thoroughly analysis is planned in order to obtain more information over the slope using the SBAS approach, also to extend the time span of analysis by processing previous available SAR images of ESA archive (ERS 1, ERS 2, ENVISAT) as well as analyzing high resolution X-band data of COSMO-SkyMed constellation.

\section{ACKNOWLEDGMENT}

We have used the computational facilities given by the infrastructure provided through the POSCCE-O 2.2.1, SMIS-CSNR 13984-901, No. 257/28.09.2010 Project, CERNESIM (L4).

\section{REFERENCES}

[1] A. Moreira, P. Prats-Iraola, M. Yuonis, G. Krieger, I. Hajnsek, and K. Papathanassiou, “A tutorial on Synthetic Aperture Radar”, IEEE Geoscience and Remote Sensing Magazine, vol. 1, pp. 6-43, March 2013.

[2] C. Colesanti and J. Wasowski, "Investigating landslides with space-borne Synthetic Aperture Radar (SAR) interferometry", Engineering Geology, vol. 88, pp. 173-199, 2006.

[3] J. Wasowski and F. Bovenga, "Investigating lanslides and unstable slopes with satellite Multi Temporal Interferometry: Current issues and future perspectives”, Engineering Geology, vol. 174, pp. 103138, 2014.

[4] A. Ferretti, C. Prati, and F. Rocca, "Nonlinear subsidence rate estimation using permanent scatterers in differential SAR interferometry”, IEEE TGRS, vol. 38, no. 5, pp. 2202-2210, 2000.

[5] A. Ferretti, C. Prati, and F. Rocca, "Permanent scatterers in SAR interferometry”, IEEE TGRS, vol. 39, no. 1, pp. 8-20, 2001.

[6] P. Berardino, G. Fornaro, R. Lanari, and E. Sansosti, “A new algorithm for surface deformation monitoring based on small baseline differential SAR interferograms”, IEEE TGRS, vol. 40, no. 11, pp. 2375-2383, 2002.

[7] V. Băcăuanu, “Alunecările de teren din partea nord-estică a Dealului Copou - Iași”, Anal. Șt. Univ. „Al. I. Cuza” Secț. a II-a XVI, pp. 143-146, 1970. (in Romanian)

[8] N. Macarovici, “Observații asupra alunecărilor de teren de la Iași din primăvara anului 1942”, Rev. șt. „V. Adamachi”, XXVIII (2-3), pp. 185-188, 1942. (in Romanian)

[9] L. Cascini, G. Fornaro, and D. Peduto, “Advanced low- and fullresolution DInSAR map generation for slow-moving landslide analysis at different scales”, Engineering Geology, vol. 112, 2010, pp. 29-42.

[10] D. Di Martire, G. De Luca, M. Ramondini, and D. Calcaterra, "Landslide-related PS data interpretation by means of different techniques”, in Landslide Science and Practice, C. Margottini, P. Canuti and K. Sassa, eds., Springer, 2013, pp. 347-355. 